\title{
How language challenges affect the behaviour of immigrant learners in the Foundation Phase at three schools in Gauteng, South Africa
}

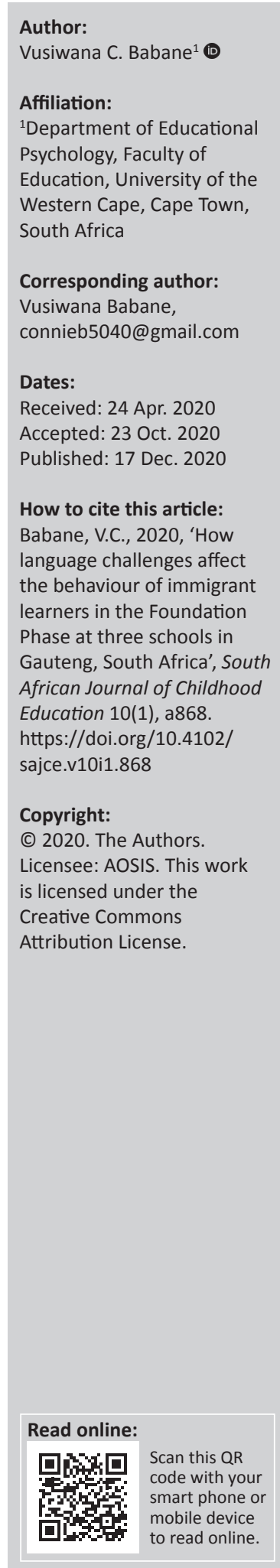

Background: The education of immigrant children is influenced by many factors that emanate from global socio-economic and political issues. In the South African education system, teachers do not have guidelines on how to include immigrant children from diverse linguistic and cultural backgrounds. The question that arose was 'what effect does poor language proficiency have on immigrant learners' psychosocial development?'

Aim: This study focused on how language challenges experienced by immigrant children influence their relationships with themselves and others in the learning environment. The second objective was to find out how teachers are coping with immigrant learners.

Setting: Learners were purposively selected from former Model C Foundation Phase classrooms in three selected schools in Gauteng province, South Africa. Former Model C schools are schools that accepted only white children prior to the early 1990s.

Methods: This study uses an interpretive research paradigm with thematic analysis of data from focus group interviews and individual interviews. Participants were 48 Foundation Phase learners, 24 female educators and three school principals.

Results: The results suggest that language barriers create a vicious cycle of negative emotions and unhealthy interactive patterns between immigrant and local children. Immigrant learners experience cognitive and social inhibition, isolation and bullying by the local learners.

Conclusion: There are implications for the integration of psychosocial content in teaching a language. This could empower Foundation Phase teachers with guidelines for teaching English to all second language learners in a way that fosters positive adjustment of immigrant children and prosocial behaviour in the learning environment.

Keywords: identity formation; prosocial behaviour; bullying; intrapersonal; interpersonal; psychosocial well-being; funds of knowledge; social identity.

\section{Introduction}

Globally, education systems are faced with the challenge of accommodating children of immigrants from various cultural and linguistic backgrounds in schools. In Africa, migration of people from one country to another has become a global phenomenon because of socio-economic challenges and political unrest. Families migrate to other countries in search of better living conditions, including education and health services for their children, amongst others. However, the grass is not always greener on the other side of the fence for involuntary immigrants, those who have had to flee their home countries for reasons beyond their control.

Voluntary immigrant families have the financial resources and literacy skills, which help their children to adjust in the education systems of their new countries (Awokoya 2009:28; Zong \& Batalova 2017). These families can also afford to send their children to private schools because they come from relatively stable countries, whereas involuntary immigrants are usually asylumseekers who come from politically unstable and war-torn countries (Ukpokodu 2018:72). Children of involuntary immigrants have to endure many challenges in their host countries.

In South Africa, these challenges include difficulty in accessing school because of education policies (Buckland 2011; Meda, Sookrajh \& Maharaj 2012:160), missing out on school because 
of families running away from violent attacks in their host communities, acculturation (Adebanji, Phatudi \& Hartell 2014:1041), adaptation and identity formation (Vandeyar 2011:3), bullying (Mohamed 2015:72) and social exclusion because they are unable to communicate in any of the South African languages. Ethnic differences amongst school children are often revealed by appearance and language, but it is mainly language that reveals their ethnic identities and highlights differences between them and local learners (Lawson-Sako \& Sachdev 2013:64; Suleiman 2013:2). Language is, therefore, a barrier to learning and psychosocial development for these children. It is for this reason that this article looks at how language challenges influence their emotional well-being as manifested in their behaviour. Language is important amongst children, especially during play. Inability to communicate with one another frustrates both the immigrant and local learners because they prefer to play with children they can communicate and identify with.

These children then divide themselves into groups, in this case, of immigrant learners and local learners, which perpetuates othering attitudes. The concept 'othering' refers to the cognitive process in which each member of these groups views a member of the outer group as 'the other'. According to Tajfel's (1974:70-71) social identity theory, othering promotes discrimination against the outer group (other group) in support of the inner group (own group). In the inner group, children are usually socialised into further 'othering' attitudes and acts of discrimination. In some South African multicultural classrooms, immigrant children are viewed and treated as aliens by the local learners, which leads to the creation of the immigrants' own in-group.

Tajfel (1974:69) defined social identity as that part of an individual's self-concept which derives from his knowledge of his membership of a social group (or groups) together with the emotional significance attached to that membership'. Language is, therefore, an emotional construct that affects one's thoughts and behaviour in social groups. When children are discriminated against, they develop a negative self-concept and low self-esteem. A low self-esteem inhibits them from participating actively in academic tasks and social activities with their peers. Othering attitudes and acts of discrimination perpetuate this inhibition. This further inhibits both the immigrant and local learners from sharing their funds of knowledge with one another. As Rovira (2008:68) asserted, language has 'the power to shape and define human experiences'.

The aim of this study was to investigate how the language challenges faced by immigrant children in the Foundation Phase classrooms of selected Former Model C schools in Gauteng province, South Africa influence their psychosocial functioning in the learning environment. The research question that guided this study was as follows: what is the influence of the immigrant children's language challenges on their emotional well-being in the learning environment? The objective was to investigate how the immigrant children's language challenges influence their emotions and behaviour in the classroom and in the playground.

\section{Research methodology}

Research methodology is a systemic description and analysis of the methods used to solve a research problem (Kallet 2004:1229; Rosnow \& Rosenthal 1996:3). A qualitative research methodology was used to address the research question because it provided the researcher with strategies to investigate and interpret the immigrant learners' thoughts and feelings within the school contexts in which these processes occur.

\section{Methods}

Qualitative research methods were used in this study. The purpose of using qualitative methods was to enable the researcher to find out the meanings immigrant learners attach to their experiences in South African classrooms with diverse linguistic and cultural backgrounds. Qualitative research methods attempt to answer the questions why, how and what (Hesser, Biber \& Leavy cited in Sebastiao 2010:24). A qualitative research design was, therefore, ideal for this study.

\section{Design}

A research design can be defined as a tool developed by the researcher as a guide on how the study will be conducted in order to address the research question as the study unfolds (Harwell 2013:148). A research design describes a set of guidelines that connect theoretical paradigms of inquiry to strategies and methods that will be used to collect the relevant data (Denzin \& Lincoln 1998:23-29). This is a case study designed within a framework of qualitative research. The concept 'case' refers to a coherent complex functioning unit of research or system that is investigated in its natural context with various methods (Yazan 2015:139). A case can be a specific individual or individuals, events, processes, institutions, organisations, locations or periods of time (David 2006:40-45). This is a case study of three former Model C schools in Gauteng North. The study was designed within the interpretive research paradigm.

\section{Sampling and setting}

A purposive sampling was used in this study and three Gauteng former Model C primary schools were selected. These schools were chosen because they had immigrant learners from various countries. The schools are situated in the centre of the city of Tshwane, the administrative capital city of South Africa. Prior to 1994, these schools had a white community's cultural identity and were aimed at the upliftment of white racial groups whilst excluding black impoverished communities (Bartlett 2016:2). Since 1994, the schools have been opened for children and teachers of all races and cultural backgrounds. Children of immigrants, 
both voluntary and involuntary, are also admitted in these schools. As explained in the second paragraph of the introduction section, voluntary immigrants usually send their children to private schools; however, some send their children to former Model C schools for various reasons, including, amongst others, convenience and proximity to their homes. Children who were selected for this study were a mixture of voluntary and involuntary immigrants.

The participants consisted of 48 Grade 3 male and female learners (eight immigrant learners and eight local learners from each school). Teachers were of different 'races' and have worked at the schools for many years. They came from various sociocultural backgrounds. Most of them stayed in the suburbs, whereas a few came from the neighbouring townships. The school principals introduced me to a contact person (head of department) for their respective schools. The contact persons helped me to identify the learners who have been at the school for a while and were able to communicate in English, although some of these children were still struggling to express themselves proficiently in English.

\section{Data collection techniques}

Various data collection methods were used in order to ascertain convergence and ensure that the findings are credible and reliable. The combination of various research instruments in a study of the same phenomenon is called 'triangulation' (Van Staden 2010:37). Triangulation crosschecks the repeated themes, gives a balanced picture of the findings, reveals contradictions, makes data interpretation valid and increases confidence in the findings (Heale \& Forbes 2013:98; Jonsen \& Jehn 2009:125-126). Data were triangulated by using focus group interviews and individual interviews.

Immigrant learners who were selected have been in these schools from at least 1 to 2 years; therefore, they could construct meaningful sentences in English. However, there were still indications of challenges with vocabulary and syntax.

For purposes of triangulation, the interview schedule was similar for all the interviews in order to ascertain that the findings are valid and reliable.

\section{Data analysis}

A qualitative thematic data analysis approach was used. A theme is a pattern identified within the data. This pattern describes and organises data in detail in the possible observations and helps in interpreting aspects of the phenomenon under study (Boyatzis 1998:161; Braun \& Clarke 2006:83-84). The patterns are 'common threads' (Morse \& Field 1995:139-140; Willig 2013:58) that are identified from data collecting instruments that address the research question. Thematic analysis was relevant for this study because it helped the researcher to 'thematise meanings' (Holloway \& Todres 2003:347) expressed by participants. It also helps to analyse data according to themes that were identified (inductively) and according to preexisting coding themes (deductively) (Braun \& Clarke 2006:83-84; Fereday \& Muir-Cochrane 2006:83). The data in this study were analysed by using a pre-existing coding frame.

The coded themes were created in accordance with the research schedule (see Appendix 2). This means that each theme was linked to a research question (see Appendix 1). The emerged data that were not pre-coded were, however, also reported and discussed.

\section{Strengths and limitations}

Through this study, data were collected from three schools that have many immigrant children. The data were triangulated; therefore, the findings are valid and reliable. However, the data were collected in one district; therefore, it cannot be generalised to all schools in South Africa.

\section{Ethical consideration}

Ethical issues were of significant importance because the investigation involved young children. Furthermore, it dealt with sensitive issues that could evoke negative feelings. The following steps were taken to ensure that ethics were upheld. Ethical clearance was obtained from the University of South Africa (UNISA) (clearance number: 2013 August/ 633433 4/CSLR).

Informed consent to access schools was obtained from the Gauteng Education Department, the school principals, teachers and parents. Children were given assent forms, which were explained to them after their parents had given consent. Participation in the study was voluntary. Participants were not forced in any form to participate in the study. All consent letters explained clearly that the participants could withdraw from the study at any time should they wish to do so.

The suggested language teaching strategy could benefit the teachers by helping them to create prosocial learning environments in multilingual and multicultural schools that have immigrant children. This would also benefit the learners because it would promote a prosocial learning environment that promotes positive social relations.

Anonymity and confidentiality were also considered. The possible risk in this study was that participants could use the interviews as a space to badmouth people they do not like and defame their character. Pseudonyms were used to minimise this risk. Schools were referred to as School A, School B and School C.

Respect and fairness was upheld amongst the participants throughout the study. Caution was taken to ensure that there was no physical or psychological harm to any of the participants. As a precautionary measure, a psychologist was 
arranged on a pro bono basis to help participants who could possibly experience negative emotions. There was, however, no incident that needed psychological intervention.

\section{Findings and discussion}

Findings revealed that poor language proficiency causes a great deal of negative emotions amongst immigrant learners. The study also revealed that language barriers create negative social interactive patterns between immigrant and local learners. Focus group interviews with the immigrant learners revealed that they experience anxiety, frustration and low self-esteem because of their inability to speak English and other South African languages fluently. These emotional states lead to cognitive inhibition, aggression and isolation amongst immigrant learners. They are, therefore, unable to participate in oral activities in the classroom and experience difficulty in forging healthy social relations with the local learners. These findings were confirmed by focus group interviews with the local learners who expressed suspicion when they cannot hear what the immigrant learners are saying in their home languages. It also emerged that the language barriers hinder the immigrant learners' identity formations and promote othering attitudes. As Tajfel (1974) asserted, identity is formed through membership in a social group. A peer group is an important social group for children at the Foundation Phase because they learn social skills through play with their peers. Isolation because of language barriers forces immigrant children to stay within their social group of foreign children, perpetuating the vicious cycle of othering.

Interviews with teachers and principals confirmed that they find including immigrant learners a major challenge as they are not equipped to teach English second-language speakers in English. It was also revealed that the staff members were not aware that learners speak different languages on the playground and that they have formed in-groups based on their home language identities and citizenship status.

Results are summarised in accordance with the predefined themes as follows.

\section{Languages used in the classroom}

I observed that English was used as a medium of instruction in the classroom. Interviews with immigrant learners, local learners, teachers and school principals, as well as the documents reviewed, confirmed that English is used as the medium of instruction in these schools. The data collection instruments also revealed that Afrikaans is used as the first additional language. The following is the view from one of the immigrant learners:

'Mam, me I know almost everything but the Afrikaans I am failing like stupid. I am not getting it right.' (Immigrant learner 1, September 2013)

It is evident from the findings that immigrant learners have a challenge of learning two languages, which are foreign to them. This negatively affects their cognitive development because language plays an essential role in the development of thought processes. Language usage involves systems of meaning, which are referred to as semiosis. It bears both referential and social meaning (Bucholtz \& Hall 2004:377). This means that a word or statement uttered in one group of people (referential) might bear a different meaning in another broader context (social). It takes an understanding of a language and culture to assign meaning appropriately in these contexts. Learning two foreign languages at the same time interferes with these processes.

The local learners who speak other South African languages other than English and Afrikaans also experience this challenge. However, they have an advantage of communicating by code-switching with their local languages, which the teachers too use as one of the strategies. The advantage that local second language learners in these schools have is that, even if they speak different languages, most of them come from communities where all these languages are spoken; therefore, they can understand each other because these languages share similar language structures. Local indigenous languages mainly spoken in these schools are Sepedi, Setswana and Isizulu. Exposure to local media could also be a factor that helps them to pick up some English vocabulary and assign meaning appropriately. This means that unlike their immigrant peers, the local learners have what can be termed 'citizenship power' that boosts their self-esteem in navigating through the language challenges in former Model C schools.

As evident in the given quotation, the self-esteem of the immigrant learners is low; hence, the participant used the concept 'stupid'. Negative emotions are also depicted in this statement. As Tajfel (1974) maintained, language is an emotional construct. Low self-esteem amongst immigrant learners stifles them from participating in verbal classroom tasks. When learners do not feel confident in English, they are likely to shy away from participation in class because they feel apprehensive and worry that they might not say the words correctly (Teaching for All 2019:62). It also inhibits their cognitive and social development because they are unable to express themselves appropriately and identify with their local peers.

\section{Languages used in the playground}

The findings show that children use various languages in the playground despite the stipulations of the school policies that the use of any other language besides English is prohibited in the school premises. Learners speak English, South African indigenous languages and various immigrant languages.

It emerged that when learners are in the playground, they make attempts to play together but later regroup themselves according to their home languages. Immigrant learners prefer to play with other immigrant learners who can speak their home languages and/or share the same citizenship status. 
Regrouping reportedly happened when some learners, either immigrants or locals, started conversing in their home languages. The following are some of the statements:

'I speak French when playing with Fufu* and David* who come from my country but speak English with my other friends ...' (Immigrant learner 2, September 2013) (Withdrawal to own social identity group)

'I usually play with my friends Funghai* and Julia* because we also play together at home. I go and play at their houses and they also visit me after school and during weekends.' (Immigrant learner 3, September 2013) (Withdrawal to own social identity group)

The findings also revealed that inability to hear what is being said creates suspicion amongst the learners as evident in the following statements. This means that these children experience foreign language anxiety both in the classroom and the playground.

'...They can like tease you in their language if you don't know it mam.' (Local learner 1, September 2013) (Suspicion)

'I don't know what they say but they, I just hear them. They just make a kind of circle and they talk about me...They look at me.' (Immigrant learner 4, September 2013) (Suspicion)

'Sometimes they (immigrant learners) can swear in their language. Like this other girl, yesterday she sweared me (swore at me) in her language.' (Local learner 2, September 2013) (Suspicion)

'We must speak English mam. English. When they (immigrant learners) speak their language... (lowers voice) they swear ....' (Local learner 3, September 2013) (Suspicion)

These statements show that both immigrant and local learners become suspicious when the 'other' group speak their home languages. Both groups suspect that the other group is gossiping about them. As explained in Tajfel's social identity theory, othering is perpetuated when in-group and out-groups are formed. Language challenges, therefore, create patterns of social exclusion, which make adaptation difficult for immigrant learners.

Interviews with teachers and principals confirmed that English is used as a language of teaching and learning at all the three schools. It also emerged that learners are expected to use only English in the playground. It was evident that principals and teachers were not aware that learners speak different languages on the playground and that they have formed in-groups based on their home language identities and citizenship status.

\section{Coping mechanisms by learners (behaviour)}

The findings also revealed that language challenges also create unhealthy interactive patterns amongst the learners. Acts of discrimination because of language barriers were reported. The following statement by Baez (2002) supports that there is a relationship between language and social behaviour:

But language not only creates the contours of identity, it also may set up the conditions for other kinds of inclusion and exclusion, belonging and not belonging, success and failure ... Language gives meaning to social structures, identity-creating and oppressive ones. (p. 124)

Social exclusion and the formation of social identity groups create bullying at these schools. The findings show that immigrant learners tend to withdraw from participation in verbal activities in the classroom because they are ridiculed. Bullying can be defined as hostile behaviour, which is repeatedly manifested physically, verbally or both and often involves power relations (O'Connell, Pepler \& Craig 1999:438). Forms of bullying include threats, sarcasm, persistent teasing, ridicule, name-calling, gossip, spreading unpleasant rumours, humiliation, exclusion from a group, tormenting and physical violence (Mncube \& Harber 2013:8). All these factors negatively affect people's emotions intensely. In these schools, bullying is more intense in the playground than in the classroom. This could be because of the fact that teachers are not in close proximity to the learners to be able to monitor their interactive patterns. The following quotations from the immigrant learners bear evidence:

'Eh, mam, they kick us and start bullying us, calling us mampara whatever, swearing to us.' (Immigrant learner 5, September 2013)

'Other children are bullying us at school, making fun of us.' (Immigrant learner 6, September 2013)

'Mam, sometimes they throw things at us. Sometimes they tease our own parents...They say your parents, your mother was born last year, your mother was born in a dustbin and all those things.' (Immigrant learner 7, September 2013)

Various immigrant learners' reactions to bullying by local learners reveal that they are frustrated and usually experience negative intrapsychic and interpsychic conflicts. Intrapsychic conflicts are internal tensions that happen in an individual's mind because of opposing forces such as drives, wishes and agencies (Nehemiah 1963:619). Interpsychic conflicts are tensions that happen between an individual and other people as a result of the 'joint functioning and reciprocal influences of two minds' (Bolognini 2004:337).

The following quotations show their behavioural reactions:

'Mam, sometimes I feel like, I wanna beat someone, like I feel, but sometimes I lock myself in the bathroom ... and when I cool down I like come out, then I eat and I fall asleep.' (Immigrant learner 1, September 2013) (Dignity preservation model; internalised anger)

'Me I sometimes I, I, I like shout at people, at that person that makes me sad.' (Immigrant learner 5, September 2013) (Pushback bullying model)

'And, yaa, every time when they are bullying me I just go to my brother and say "I can't take (it when) every child (is) taking advantage of me and bullying me so I also have to fight back." (Push-back bullying model) but sometimes violence is not the right thing.' (Immigrant learner 7, September 2013) 
These quotations show that immigrant learners often use destructive coping mechanisms to deal with their frustrations. As Tajfel (1974:66) explained, this behaviour can be associated with Dollard's frustration-aggression hypothesis. According to this hypothesis, 'aggression is always a consequence of frustration' (Dollard et al. 1939:1). If the thwarted individuals do not react to frustration with aggression, it is often because of fear of punishment; as a result, they usually harm themselves or innocent people around them (Berkowitz 1989:61; Dollard et al. 1939:7). This is evident in the findings of this study. The following statement from an immigrant learner bears evidence:

'Me mam, when I am sad I'm like banging myself, pulling my hair, pulling my ears... I go to the bathroom and do it...I'm angry, I'm no more talking to anyone. So they ask me "are you angry, why are you angry" and whatever. Then I tell them I am not angry I'm just sleepy.' (Immigrant learner 7, September 2013) (self-punishment)

According to Mthethwa-Sommers and Kisiara (2015), there are different ways in which thwarted individuals resist and cope with bullying. They refer to these ways as models. Three of the four models in which children cope with bullying were reported: the 'push-back' model, which means that the victim counter-bullies the bully either verbally or physically; the dignity preservation model, which involves hiding one's true emotions in front of the bully and expressing the anger in secret; and the self-punishment model, which involves inflicting pain on oneself with the hope that the physical pain will decrease the emotional pain. The fourth model is called external validation and it is manifested by the victim's attempts to reduce bullying by reporting the bullies to someone in authority or forging friendships with the bully and/or his friends (Mthethwa-Sommers \& Kisiara 2015:4-5). This implies that language barriers have a negative influence on the immigrant children's psychosocial well-being. The concept 'psychosocial well-being' refers to people's 'mental, emotional and social health - how we feel about ourselves, the quality of our social interactions with others and our sense of belonging in our communities' (Teaching for All 2019:17).

\section{Support strategies by teachers}

Teachers reported that they use various strategies to support immigrant learners and other learners whose first language is not English. The strategies include scaffolding, repetition of lessons, role plays, paired reading, code-switching, audiovisuals and extra English lessons after school. It also emerged that during code-switch, only two South African languages - that is, Sepedi and Setswana - that are mainly spoken in Tshwane are used. This means that children who do not understand these languages are still disadvantaged. These findings, therefore, also reveal that learners are experiencing cultural dissonance in these schools and those schools still need to work on to improve on issues of cultural consonance.

The involvement of the parents for assistance with tasks and translations of tasks were also stated. Teachers in one of embassies in one of the schools were also reported. The teachers explained that they involve the relevant embassy for children whose parents are not able to communicate well in English. One of the teachers stated that:

'We had a Grade 3 child from Eritrea who couldn't understand a single word in English and his parents couldn't help either because they also couldn't speak English ... We had to seek help from their embassy. We do the same with French and Portuguese learners who have the same challenge...' (Teacher 1 at School A, September 2013)

The findings bear evidence that language challenges prevent immigrant learners from forming appropriate social relations with themselves and with their local peers. Identity formation is also a challenge to these learners as they have to learn in a foreign language in which they are teased. They, therefore, keep to their own language and/or citizenship identity groups. In the process, both immigrant and local learners lose out on each other's cultural funds of knowledge. The children's closest system, the microsystem, plays a significant role in their holistic development. This system consists of family members, teachers and peers. It is, therefore, important that the child has healthy relationships with his or her teachers and peers in order to develop holistically.

My contention is that the othering attitudes based on language barriers can be addressed by including prosocial teaching strategies in teaching English as a language of teaching and learning to second-language speakers. This would help alleviate unhealthy interactive patterns and othering attitudes. As Anning and Ring (2004:5) asserted, it is through narratives that children are able to explain and assign meaning to their life experiences. Narratives also help them to deal with unpleasant emotions and behaviour (SirajBlatchford et al. 2002:12; Vetere \& Dowling 2005:194-195).

The strategies include pairing of learners in accordance with home language proficiency, encouraging multilanguaging, code-switching and, in cases where the learner is the only child speaking that language at the school, seeking support from the family and the embassy.

\section{Recommendations}

This article proposes that language teaching should integrate psychosocial content in order to support immigrant learners cognitively and emotionally. This will promote prosocial behaviour in schools. The concept of prosocial behaviour is the opposite of antisocial behaviour, which refers to behaviour that is disruptive, aversive, annoying or harmful to others. Bullying is an example of antisocial behaviour.

Prosocial behaviour can be defined as behaviour that supports positive social interactions and 'benefits others or promotes harmonious relationships' (Bergin 2018:2). Prosocial education is related to social-emotional learning, which consists of five core competencies: self-management, self-awareness, responsible decision-making, social awareness and relationship skills. Each of these competencies belongs to either the intrapersonal or interpersonal skills. 
Intrapersonal skills include skills such as self-control, positive mindset that promotes growth and setting goals. Interpersonal skills include social skills such as positive interactive patterns with others, which is also referred to as prosocial behaviour (Bergin 2018:4).

The integrative multilingual narrative approach in teaching a language is advocated in this study because multilanguaging helps in promoting cultural consonance and identity formation (Tajfel 1974). It also makes learning fun and promotes prosocial behaviour. The integrative multilingual narrative approach is the teaching approach that draws content from different cultural contexts, integrates content from various subject areas and engages the learners holistically through narratives. The approach is also supported by Bruner's theory of narrative construction of reality, which states that human beings construct and impart knowledge by means of narratives (Bruner 2004:692). This approach is suitable for children in the Foundation Phase because children in this phase learn effectively through narratives (Murris \& Verbeek 2014:12). It also ensures that all diverse learners feel included in the classroom. It is thus important that their voice is used to pioneer their learning processes.

The integrative multilingual narrative approach does not use a single method or strategy but combines different kinds of narrative strategies to develop and implement curriculum content. As Bruner (2004) asserted, life itself is a narrative because narratives happen in different ways in people's daily lives.

The following are examples of prosocial strategies that can be used:

- Use culturally inclusive visuals (pictures and videos) in order to alleviate foreign language anxiety and language and accent-based bullying: Ask learners to say what the visual is called in their language, write it down and use the shared vocabulary to teach reading. This approach will add the learners' cultures and languages to English and Afrikaans. As Desai (2016:346) asserted, 'we should adopt a "two plus" approach in addressing language issues' as opposed to a "two minus" approach' which promotes English monolingualism and Afrikaans as the first additional language. When learners narrate and discuss their cultural aspects, they feel connected to the learning content and become interested in learning about other learners' cultures instead of ridiculing one another. This strategy also addresses cultural dissonance that children usually feel when they suddenly find themselves in a culture that is different from their own.

- Ask learners to list prosocial behaviour they would like to see at their school: Then they should identify a classmate who models prosocial behaviour in their class and describe the kinds of prosocial behaviours he or she models. This will foster discussions about empathy and love towards their peers. It is advisable to write down the learner's contributions on the flip charts and paste them on the wall as daily reminders of their commitment to promoting a healthy learning environment for all.

- Give children a chance to build stories on sand trays: Sand has a grounding or 'earthing' effect on human beings as it connects us to the earth. Earthing refers to the human body's direct contact with the electrons that are found on the surface of the earth that promote physiological and psychological well-being (Chevalier 2015:534). Playing with sand helps children to deal with their inner states, which promotes intrapersonal and interpersonal relations.

- Collect miniatures or symbols from diverse cultures and ask each child to choose the symbols he or she would like to play with. Then ask them to share their stories. This is an adaptation of a therapeutic strategy used by psychologists and it could evoke emotions amongst children. It must, therefore, be used cautiously and referral to professionals should be done as soon as the teacher identifies discomfort or negative emotions. Children should not be forced to share their stories if they show signs of discomfort.

- Sandplay facilitates communication in children with language barriers and children who come from various languages and cultures. Building stories on sand gives them a safe environment in which they express themselves according to their unique personalities (Campbell 2004:4). Learning by manipulating symbols is also essential for their level of development (Gardner 1993:11-12).

- The miniature symbols that children use in Sandplay help them to create their own fantasy worlds. The stories they build also depict their understanding of the world and the meanings they assign to their realities. This means that Sandplay provides learners with an opportunity to develop their intrapersonal intelligence, which is needed to construct their selfesteem. Intrapersonal intelligence is essential in promoting prosocial behaviour because it teaches individuals self-awareness, how to manage emotions, empathy and how to handle relationships with others (Hoerr, Boggeman \& Wallach 2010:43; Shearer 2006:5).

- Encourage children to share indigenous games: Through play, children express their cultural narratives (Roux cited in Roux 2009:585). Indigenous games would give immigrant and local children an opportunity to share their diverse cultural funds of knowledge, thereby promoting prosocial behaviour. In cross-cultural play, 'diverse funds of knowledge intermingle...' (De SotoMadson 1977:3). When different cultures intermingle in the learning environment, new curriculum content is created, which can be used by teachers to develop the curriculum and address multilingualism in teaching their classrooms. A prosocial learning environment enables children to navigate social interactions in their microsystems positively. Immigrant children would be able to forge friendships with their peers without being constantly reminded of their citizenship status. Bullying is thus alleviated. 
- Include digital storytelling in pedagogy: Digital storytelling is a narration of a story by using various media such as cameras, video recorders, computers and smart boards that enable children to voice out their thoughts and emotions. By telling their stories digitally, children construct their own content because they use their own pictures and vocabulary to tell the stories. Sharing digitally constructed personal narratives is empowering to teachers and learners in a multilingual classroom as it creates a cross-cultural community (Benmayor 2008:188-189; Condy et al. 2012:279; Lum 2013:51). Through digital storytelling, immigrant children could have a sense of belonging to a community, which promotes prosocial behaviour.

- Promote critical thinking through rewriting stories: Rewriting stories means rethinking and recreating a story by interpreting it differently and assigning a new meaning. When children rewrite a story, they interpret it from their own cultural perspectives, use their own language toolkits and become aware of other children's languages and cultures. It also strengthens the bond between the school and the community (Lotherington 2007:242). Relationships between members of the family-school mesosystem are strengthened because parents feel that they are part of the school community. This narrows the 'us' and 'them' attitude gap between parents and teachers.

- Encourage self-expression by using visual and performing arts: Drawing, painting, poetry, music, drama and dance are ideal forms of arts that help in teaching Foundation Phase children how to express their talents and emotions positively. Performing arts such as drama and dance help teach children how to respect their peers' personal space (Shapiro 1998:15). This means that through arts children also learn to recognise boundaries, which promotes prosocial behaviour towards others. This could, therefore, alleviate bullying. Singing songs in their own languages fosters cultural consonance, self-identity formation and respect for other children's identities.

- Create a warm classroom environment, which includes multilanguaging and humour in language teaching in order to promote interest in learning the language: Humour fosters prosocial behaviour because it redirects the child's attention from negative thoughts and feelings to positive engagement with others. However, teachers should guard against using humour that could offend some children. Patronising children should be avoided at all costs because it defeats the purpose. A teacher could use humour to introduce lesson, simplify a lesson, give a task, make an announcement, dissolve tensions in class or remind children of their commitment to prosocial behaviour.

\section{Conclusion}

This study provides evidence that immigrant learners' language challenges affect their emotional well-being negatively and inhibit them from participating effectively in the learning environment. Negative emotions result in unhealthy interactive patterns with their peers, which bar them from sharing their funds of knowledge with others. A prosocial learning environment needs to be created as a basis to support immigrant learners in order to ensure a healthy adjustment and continued healthy intrapersonal and interpersonal relationships amongst all learners.

The suggested approach to language teaching helps teachers to involve children in sharing and constructing their own curriculum content, which is an essence of co-operative learning and promoting prosocial behaviour. It also fosters the use of language as an asset for inclusive education instead of a barrier to learning and development. Through the Teaching for All Project, the South African education system is currently moving in the right direction. The Teaching for All Project is a partnership between various institutions, including the British Council, the University of South Africa, the South African Departments of Basic Education and Higher Education and Training and MIET Africa. It is co-funded by the European Union. The aim of this project is to empower teachers with knowledge, skills and attitudes that will enable them to cope with and teach inclusively in classrooms with diverse learners who come from diverse communities.

\section{Acknowledgements}

The author would like to thank the University of South Africa (UNISA) for the data used in this article. The data were extracted from the author's doctoral thesis entitled 'Educational challenges of immigrant children at selected Foundation Phase schools in South Africa'. The author also expresses her gratitude to Prof. Ellen Lenyai, UNISA, for her guidance in this study and Prof. Zubeida Desai, University of the Western Cape (UWC), for working tirelessly to edit this article.

\section{Competing interests}

The author has declared that no competing interests exist.

\section{Author's contributions}

I declare that I am the sole author of this research article.

\section{Funding information}

The thesis from which the data were extracted was funded by the University of South Africa and also financially supported by the Department of Higher Education and Training (DHET) through Cape Peninsula University of Technology.

\section{Data availability statement}

The data was extracted from a doctoral thesis.

\section{Disclaimer}

The views and opinions expressed in this article are those of the author and do not necessarily reflect the official policy or position of any affiliated agency of the author. 


\section{References}

Adebanji, O.T., Phatudi, N.C. \& Hartell, C.G., 2014, 'The influence of familial and schooling experiences on the acculturation of immigrant children from Zimbabwe', Mediterranean Journal of Social Sciences 5(20), 1039-1050. https:// doi.org/10.5901/mjss.2014.v5n20p1039

Anning, A. \& Ring, K., 2004, Making sense of children's drawings, McGraw-Hill, Berkshire.

Awokoya, J.T., 2009, “'I'm not enough of anything!": Racial and ethnic identity constructions and negotiation of one-point-five and second generation Nigerians www.semanticscholar.org.

Baez, B., 2002, 'Learning to forget: Reflections on identity and language', Journal of Latinos and Education 1(2), 123-132. https://doi.org/10.1207/S1532771XJLE0102 4

Bartlett, H., 2016, 'Exploring the "educational engagement" processes at a former model C high school in Cape Town', Thesis presented for the Degree of Maste in Education (Education Policy Studies), March 2016, University of Stellenbosch, Cape Town.

Benmayor, R., 2008, 'Digital storytelling as a signature pedagogy for the new humanities', Arts \& Humanities in Higher Education 7(2), 188-204. https://doi. org/10.1177/1474022208088648

Bergin, C., 2018, Designing a prosocial classroom - Fostering collaboration in students from Pre-K -12 with the curriculum you already use, W.W. Norton and Company, New York, NY.

Berkowitz, L., 1989, 'Frustration-aggression hypothesis: Examination and reformulation', Psychological Bulletin 106(1), 59-73. https://doi.org/10.1037/0033-2909.106.1.59

Bolognini, S., 2004, 'Intrapsychic-interpsychic', International Journal of Psychoanalysis 85(2), 337-357. https://doi.org/10.1516/375F-R1HW-NX8X-96F0

Boyatzis, R., 1998, Transforming qualitative information: Thematic analysis and code development, Sage, Thousand Oaks, CA.

Braun, V. \& Clarke, V., 2006, 'Using thematic analysis in psychology', Qualitative Research in Psychology 3(2), 77-101. https://doi.org/10.1191/1478088706qp063oa

Bruner, J., 2004, 'Life as narrative', Social Research 71(3), 691-710.

Bucholtz, M. \& Hall, K., 2004, 'Language and identity', in A. Duranti (ed.), A companion to linguistic anthropology, pp. 369-394, Blackwell, Hoboken, New Jersey. https://doi. org/10.1002/9780470996522.ch16

Buckland, S., 2011, 'From policy to practice: The challenges to educational access for non-nationals in South Africa', International Journal of Educational Development 31(4), 367-373. https://doi.org/10.1016/j.ijedudev.2011.01.005

Campbell, M.A., 2004, 'The value of Sandplay as a therapeutic tool for school guidance counsellors', Australian Journal of Guidance and Counselling 14(2), 211-232. https://doi.org/10.1017/S103729110000251X

Chevalier, G., 2015, 'The effects of grounding the human body on mood', Psychological Reports: Mental \& Physical Health 116(2), 534-542. https://doi.org/10.2466/06. PR0.116k21w5

Condy, J., Chigona, A., Gachago, D. \& Ivanla, E., 2012, 'Pre-service students' perceptions and experiences of digital storytelling in diverse classrooms', TOJET: The Turkish Online Journal of Educational Technology 11(3), 278-285.

David, M., 2006, Case study research, Sage, Durham, NC.

Denzin, K. \& Lincoln, Y.S., 1998, The landscape of qualitative research - Theories and issues, Sage, Thousand Oaks, California.

Desai, Z., 2016, 'Learning through the medium of English in multilingual South Africa: Enabling or disabling learners from low income contexts?', Comparative Education 52(3), 343-358. https://doi.org/10.1080/03050068.2016.1185259

De Soto-Madson, K., 1977, Play in the multilingual classroom, University of North Carolina, Learn, NC, viewed 16 April 2020, from www.learnnc.org/Ipeditions/ Carolina, Learn, $\mathrm{NC}$,
brdglangbarriers $/ 2.3$.

Dollard, J., Doob, L., Miller, N., Mowrer, O. \& Sears, R., 1939, Frustration and aggression, Yale University Press, New Haven, CT.

Fereday, J. \& Muir-Cochrane, E., 2006, 'Demonstrating rigor using thematic analysis: A hybrid approach of inductive and deductive coding and theme development', International Journal of Qualitative Methods 5(1), 80-92. https://doi. org/10.1177/160940690600500107

Gardner, H., 1993, Multiple intelligences: The theory in practice, Basic Books, New York, NY.

Harwell, M.R., 2013, 'Research design in qualitative/quantitative/mixed methods', in C.F. Conrad \& R.C. Serlin (eds.), The Sage handbook for research in education: Pursuing ideas as the keystone of exemplary inquiry, pp. 147-182, Thousand Oaks, Pursuing ideas
California.

Heale, R. \& Forbes, D., 2013, 'Understanding triangulation in research', Evidence Based Nursing 16(4), 98. https://doi.org/10.1136/eb-2013-101494

Hoerr, T.R., Boggeman, S. \& Wallach, C., 2010, Celebrating every learner: Activities and strategies for creating a multiple intelligence classroom, Jossey-Bass, San Francisco, CA.

Holloway, I. \& Todres, L., 2003, 'The status of method: Flexibility, consistency and coherence', Qualitative Research 3(2), 345-357. https://doi.org/10.1177/ 1468794103033004

Jonsen, K. \& Jehn, K.A., 2009, 'Using triangulation to validate themes in qualitative studies', Qualitative Research in Organizations and Management: An Internationa Journal 4(2), 123-150. https://doi.org/10.1108/17465640910978391

Kallet, R.H., 2004, 'How to write the methods section of a research paper', Respiratory Care 49(10), 1229-1232.
Lawson-Sako, S. \& Sachdev, I., 2013, 'Ethnolinguistic communication in Tunisian streets: Convergence and divergence', in Y. Suleiman (ed.), Language and identity in the Middle East and North Africa, pp. 61-79, Routledge, New York, NY.

Lotherington, H., 2007, 'Rewriting traditional tales as multilingual narratives at elementary school: Problems and progress', Canadian Journal of Applied Linguistics 10(2), 241-256.

Lum, C.H., 2013, Contextualized practices in arts education: An international dialogue on Singapore, Springer, Singapore.

Meda, L., Sookrajh, R. \& Maharaj, B., 2012, 'Refugee children in South Africa: Access and challenges to achieving universal primary education', Africa Education Review 9(1), 152-168. https://doi.org/10.1080/18146627.2012.755287

Mncube, V. \& Harber, C., 2013, The dynamics of violence in South African schools: Report, University of South Africa, Pretoria.

Mohamed, A., 2015, 'The scholastic experiences of immigrant learners at a secondary school in Sydenham', A dissertation Submitted in fulfilment of the requirements
of the degree of Master of Education (Educational Psychology), College of of the degree of Master of Education (Educational Psych
Humanities, School of Education, University of KwaZulu-Natal.

Morse, J.M. \& Field, P.A., 1995, Qualitative research methods for health professionals, Sage, Thousand Oaks, CA.

Mthethwa-Sommers, S. \& Kisiara, O., 2015, 'Listening to students from refugee backgrounds: Lessons for education professionals', Perspectives on Urban Education 12(1), viewed 18 April 2020, from www.urbanedjournal.org/.../ listening-students-refugee-backgrounds-lessons-education-profe.

Murris, K. \& Verbeek, C., 2014, 'A foundation for foundation phase teacher education: Making wise educational judgements', South African Journal of Childhood Education 4(2), 1-17. https://doi.org/10.4102/sajce.v4i2.201

Nehemiah, J.C., 1963, 'The significance of intrapsychic conflict', Report presented at the Fall Meeting of the American Psychoanalytic Association, December 1962, New York, NY, viewed 13 April 2020, from https://journals.sagepub.com/doi/abs/10.

O'Connell, P., Pepler, D. \& Craig, W., 1999, 'Peer involvement in bullying: Insights and challenges for intervention', Journal of Adolescence 22(4), 437-452, Pearson, Riverside. https://doi.org/10.1006/jado.1999.0238

Rosnow, R.L. \& Rosenthal, R., 1996, Beginning behavioral research - A conceptual primer, Prentice-Hall International, Pearson, Riverside.

Roux, C., 2009, 'Integrating indigenous games and knowledge into physical education: Implications for education and training in South Africa: Physical education and
sport science', African Journal for Physical, Health Education, Recreation and sport science', African Journal for Physical, Health Education, Recreation and
Dance (AJPHERD) 15(4), 583-593. https://doi.org/10.4314/ajpherd.v15i4.49545

Rovira, L.C., 2008, 'The relationship between language and identity: The use of the home language as a human right of the immigrant', Revista Interdisciplinar da Mobilidade Humana 16(31), 63-81.

Sebastiao, M.N., 2010, 'An investigation into the causes of Mozambican teenage migration into South Africa', B. Tech dissertation, Cape Peninsula University of Technology, Cape Town.

Shapiro, S.B., 1998, 'Toward transformative teachers: Critical and feminist perspectives in dance education', in S.B. Shapiro (ed.), Dance, power and difference: Critical and feminist perspectives on dance education, pp. 7-21, Human Kinesthetics, Champaign, IL.

Shearer, C.B., 2006, 'Reading skill and the multiple intelligences: An investigation into the MI profiles of high school students with varying levels of reading skill', viewed 30 May 2020, from www.miresearch.org/files/Reading_MI.doc.

Siraj-Blatchford, I., Sylva, K., Muttock, S., Gilden, R. \& Bell, D., 2002, Researching effective pedagogy in the early years, Research Report RR356, University of London and University of Oxford, Oxford.

Suleiman, Y., 2013, Language and identity in the middle east and North Africa, Routledge, London.

Tajfel, H., 1974, 'Social identity and intergroup behaviour', Social Science Information 13(2), 65-93. https://doi.org/10.1177/053901847401300204

Teaching for All., 2019, Inclusive teaching and learning for South Africa, Unit 2 Learner diversity, British Council, Parklands, viewed 16 April 2020, from https:// fundaoer.org/guides/teaching-for-all/.

Ukpokodu, O.N., 2018, 'African immigrants, the "New Model Minority": Examining the reality in U.S. k-12 schools', Urban Review 50(1), 69-96. https://doi.org/10.1007/ s11256-017-0430-0

Vandeyar, S., 2011, 'Immigrant students' shifting identifications in South African schools', International Journal of Education Development 32(2), 232-240. https:// doi.org/10.1016/j.ijedudev.2011.03.006

Van Staden, S.Q., 2010, 'Teaching strategies utilised by non-special education teachers in inclusive further education and training classrooms', A dissertation submitted in partial fulfilment of the requirements of the Magister Educationis (Education Management), Cape Peninsula University of Technology, Cape Town.

Vetere, A. \& Dowling, E., 2005, Narrative therapies with children and their families. A practitioner's guide to concepts and approaches, Routledge, London.

Willig, C., 2013, Introducing qualitative research in psychology, McGraw-Hill, New York, NY.

Yazan, B., 2015, 'Three approaches to the case study methods in education: Yin, Merriam, and Stake', The Qualitative Report 20(2), 134-152.

Zong, J. \& Batalova, J., 2017, African immigrants in the United States, viewed 15 April 2020, from http://www.migrationpolicy.org/article/sub-saharan-africanimigrants-united-states. 


\section{Appendix 1: Research schedule Interviews with immigrant learners}

1. Which language do you use to communicate with your teachers and friends in the classroom?

2. Which language do you use to communicate with your friends in the school ground? Probing questions: How do you feel when other learners speak different languages that you do not understand in your classroom and on the school ground? What do you do when you feel that way?

\section{Interviews with local learners}

1. Which language do you use to communicate with your teachers and friends in the classroom?

2. Which language do you use to communicate with your friends in the school ground? Probing questions: How do you feel when immigrant learners speak different languages that you do not understand? What do you do when you feel that way?

\section{Interviews with teachers}

1. Which language do you use to teach and communicate learners in the classroom?

2. Probing question: What do you do to support learners who experience difficulty in speaking English?

3. Which language(s) do learners use in the school ground?

\section{Interviews with principals}

1. What is the language of teaching and learning at your school?

2. Probing question: What measures are in place to support learners who experience difficulty in speaking English at your school?

3. Which language(s) are learners expected to use to communicate with each other in the playground?

\section{Appendix 2: Coding frames}

- Languages used in the classroom

- Languages used in the playground

- Coping mechanisms by learners

- Support strategies by teachers 